Syntax Fusion: Jurnal Nasional Indonesia

e-ISSN: 2775-4440

Vol. 1, No. 10, Oktober 2021

\title{
SISTEM INFORMASI PENGOLAHAN DATA NILAI BERBASIS WEB PADA SMK SWADAYA TEMANGGUNG
}

\author{
Dina Oktaviana, Nur Kumala Dewi \\ STMIK Muhammadiyah Jakarta, Indonesia \\ Email: dinaa.oktav@gmail.com,nkd.mandori@gmail.com
}

\begin{abstract}
Abstrak
Sistem informasi pengolahan Data Nilai Siswa di SMK Swadaya Temanggung masih manual masih berupa kertas raport yang ditulis tangan oleh wali kelas sehingga tidak efektif dan membutuhkan waktu yang lebih lama untuk melihat nilai siswa. Penulis bermaksud melakukan penelitian dengan tujuan untuk mendapatkan solusi terhadap permasalahan tersebut. Solusi yang ditawarkan adalah dengan membuat Sistem Informasi Pengolahan Data Nilai Siswa di SMK Swadaya Temanggung. Metodologi penelitian yang digunakan yaitu metodologi pengembangan sistem waterfall yang terdiri dari Requirements Analysis and Definition, System and Software Design, Implementation and Unit Testing, Integration and System Testing, dan Operations and Maintenance. Bahasa Pemrograman yang dipilih yaitu PHP dan MySql untuk menangani databasenya. Hasil dari penelitian menunjukkan bahwa Sistem Informasi Pengolahan Data Nilai Siswa Berbasis Web Pada SMK Swadaya Temanggung mampu menyelesaikan atau meminimalisir permasalahan yang ada. Dengan adanya sistem ini proses penginputan nilai siswa akan lebih cepat dan efektif sehingga walimurid dapat melihat nilai dan absensi siswa.
\end{abstract}

Kata Kunci: Sistem Informasi; Data Nilai; PHP; MySQL

Diterima: 29-09-2021 Direvisi: 15-10-2021 Disetujui: 18-10-2021

\section{Pendahuluan}

Perkembangan teknologi mengalami perkembangan yang sangat pesat. Seiring dengan berjalannya waktu teknologi informasi dan komunikasi suatu hal yang penting untuk masyarakat terutama untuk mempermudah kalangan guru dalam menginput data nilai saat ini yang sangat diperlukan. Cara untuk memudahkan guru dan wali murid dalam hal menyimpan nilai, salah satunya SMK Swadaya yang sudah saatnya mengembangkan sistem agar mampu mengikuti perkembangan zaman.

SMK Swadaya Temanggung yang terletak di JL. Giling Sari No.2 Temanggung, sekolah ini terletak di tempat yang strategis, sistem penginputan data nilai di sekolah ini masih menggunakan cara manual sehingga membutuhkan waktu yang cukup lama. 
Penggunaan web di SMK Swadaya Temanggung akan memudahkan proses penginputan data nilai siswa sehingga guru lebih mudah untuk menginput data nilai di halaman web melalui komputer, sehingga tidak perlu lagi menginput data nilai secara manual.

Oleh karena itu dibutuhkan sistem pengolahan data nilai yang berbasis komputer, sehingga mempermudah dalam menginput nilai dan walimurid cek nilai serta terhindarnya dari kehilangan data, karena data yang ada tersimpan dalam database serta mempermudah dalam pembuatan laporan. Menurut Dr. Ir. Harijono Djojodihardjo (Djojodihardjo, 2017), bahwa sistem adalah kumpulan objek, yang meliputi hubungan fungsional antara setiap objek dan hubungan antara karakteristik setiap objek, secara keseluruhan adalah satu kesatuan fungsional.

Sedang menurut Jogiyanto yang mendefinisikan Sistem Ini adalah kumpulan elemen yang berinteraksi untuk mencapai tujuan tertentu. Sistem menggambarkan peristiwa dan entitas nyata, seperti tempat, benda, dan orang yang benar-benar ada dan terjadi (Jogiyanto, 2016). Dapat dikatakan bahwa sistem sistem merupakan suatu paduan yang terdiri dari beberapa elemen atau unsur yang digabungkan menjadi satu kesatuan sehingga memudahkan aliran informasi dan material atau energi untuk mencapai suatu tujuan tertentu (Kadir, 2003).

Informasi merupakan hal terpenting dalam sebuah sistem. Informasi dapat diartikan sebagai pemberitahuan yang dibawa oleh informan berupa data yang telah diolah agar lebih bermanfaat dan berguna bagi penerimanya tentang segala sesuatu yang terjadi disekitarnya dan bersifat nyata atau faktual (McLeod \& Schell, 2004). Sistem TI adalah sistem dalam organisasi yang memenuhi kebutuhan pemrosesan transaksi harian, mendukung operasi, merupakan manajemen dan aktivitas strategis organisasi, dan menyediakan beberapa entitas eksternal dengan laporan yang diperlukan. (Jogiyanto, $\underline{2005)}$.

Sesuai dengan ketentuan Peraturan Menteri Pendidikan Nasional Nomor 20 Tahun 2007 tentang Standar Penilaian Pendidikan, tutor dalam hal ini adalah guru yang setiap akhir semester melaporkan hasil penilaian mata pelajaran kepada kepala sekolah. Satuan pendidikan berupa hasil tunggal prestasi siswa dengan uraian singkat sebagai cerminan kompetensi penuh (Dasar, 2006).

Nilai adalah konsep umum tentang hal-hal yang dianggap baik, pantas, berharga, dan pantas keberadaannya diinginkan, dihayati, dan diimplementasikan dalam kehidupan sehari-hari, serta menjadi tujuan hidup bersama dalam masyarakat. Berdasarkan suku, bangsa, dan masyarakat internasional. Nilai merupakan salah satu kriteria keberhasilan peserta didik untuk mengenyam pendidikan di sekolah (Sutarjo, 2012).

Pendidikan menengah kejuruan adalah jenjang pendidikan menengah yang mengutamakan pengembangan kemampuan siswa untuk melakukan jenis pekerjaan tertentu. Pendidikan menengah kejuruan memberikan prioritas untuk mempersiapkan siswa memasuki pasar kerja dan mengembangkan sikap profesional. Sekolah Menengah Kejuruan menyelenggarakan program pendidikan yang sesuai dengan jenis pekerjaan sesuai dengan bentuknya (Djojonegoro \& Slamet, 1998) 


\section{Metodologi Penelitian}

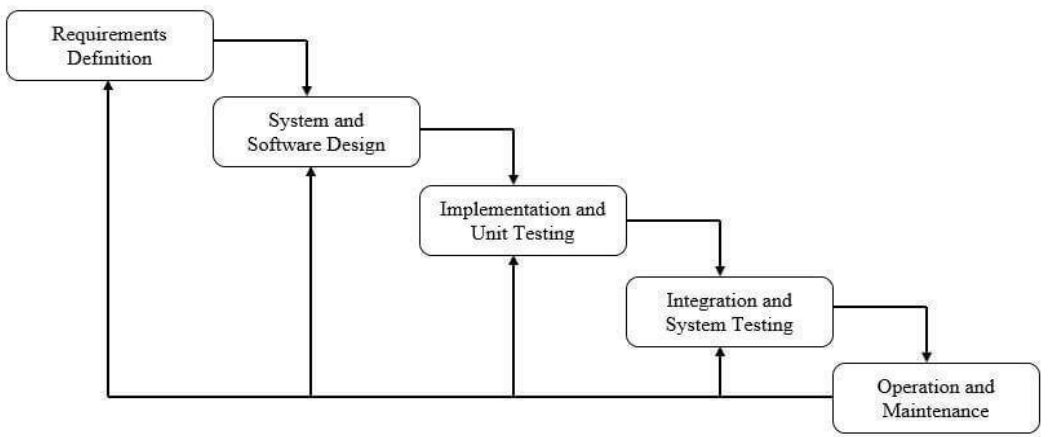

Gambar 1. Metode Waterfall

Metode waterfall atau metode air terjun adalah salah satu siklus hidup klasik dalam pengembangan perangkat lunak. Ian Sommerville menjelaskan bahwa metode waterfall memiliki lima tahapan, yaitu analisis dan definisi kebutuhan, perancangan sistem dan perangkat lunak, implementasi dan pengujian unit, integrasi dan pengujian sistem, serta operasi dan pemeliharaan (Ian Sommerville, 2011). Metode waterfall terdiri dari 5 tahapan yaitu:

\section{Requirement Definition}

Sebelum mengembangkan perangkat lunak, pengembang harus mengetahui dan memahami bagaimana pengguna membutuhkan informasi tentang perangkat lunak.

2. System and Software Design

Kemudian pada tahap ini, informasi tentang spesifikasi kebutuhan dari tahap analisis kebutuhan dianalisis, kemudian diimplementasikan dalam pengembangan dan perancangan. Tujuan dari perancangan adalah untuk membantu memberikan gambaran lengkap tentang pekerjaan yang harus dilakukan.

3. implementation and unit testing

Tahap implementasi dan pengujian unit adalah tahap pemrograman. Pengembangan perangkat lunak dibagi menjadi modul-modul kecil, yang akan digabungkan pada tahap berikutnya.

4. Integration and System Testing

Setelah seluruh unit atau modul yang dikembangkan dan diuji di tahap implementasi selanjutnya diintegrasikan dalam sistem secara keseluruhan.

5. Operation dan Maintenance

Pada tahap terakhir dalam Metode Waterfall, perangkat lunak yang sudah jadi dioperasikan pengguna dan dilakukan pemeliharaan. 


\section{Hasil dan Pembahasan}

\section{Analisa kebutuhan perangkat keras}

Adapun kebutuhan minimum dan yang disarankan untuk menggunakan aplikasi Sistem Informasi Pengolahan Data Nilai Berbasis Web pada SMK Swadaya Temanggung adalah sebagai berikut:

Tabel 1. Kebutuhan perangkat keras (Hardware)

\begin{tabular}{|c|c|c|}
\hline $\begin{array}{l}\text { No } \\
.\end{array}$ & Jenis & Komponen \\
\hline 1 & $\mathrm{CPU}$ & Intel Pentium \\
\hline 2 & Memori (RAM) & 4GB \\
\hline
\end{tabular}

\section{Analisa kebutuhan perangkat lunak}

Adapun perangkat lunak untuk membangun program ini adalah sebagai berikut:

Tabel 2. Kebutuhan perangkat lunak (Software)

\begin{tabular}{ccc}
\hline No. & Jenis & Komponen \\
\hline 1 & Software & Xampp \\
\cline { 3 - 3 } & & Wondershare EdrawMax \\
\cline { 2 - 3 } & & Notepad++ \\
\cline { 3 - 3 } & & Bootstrap \\
\hline 2 & Database & MySQL \\
\hline 3 & Operation System & Windows 10 \\
\hline
\end{tabular}

\section{Analisa Sistem Yang Berjalan}

Sistem pengolahan data nilai saat ini digunakan pada SMK Swadaya Temanggung masih manual mengalami beberapa kendala seperti keterlambatan pengumpulan data, penyimpanan data yang bertumpuk sehingga ada beberapa data yang hilang

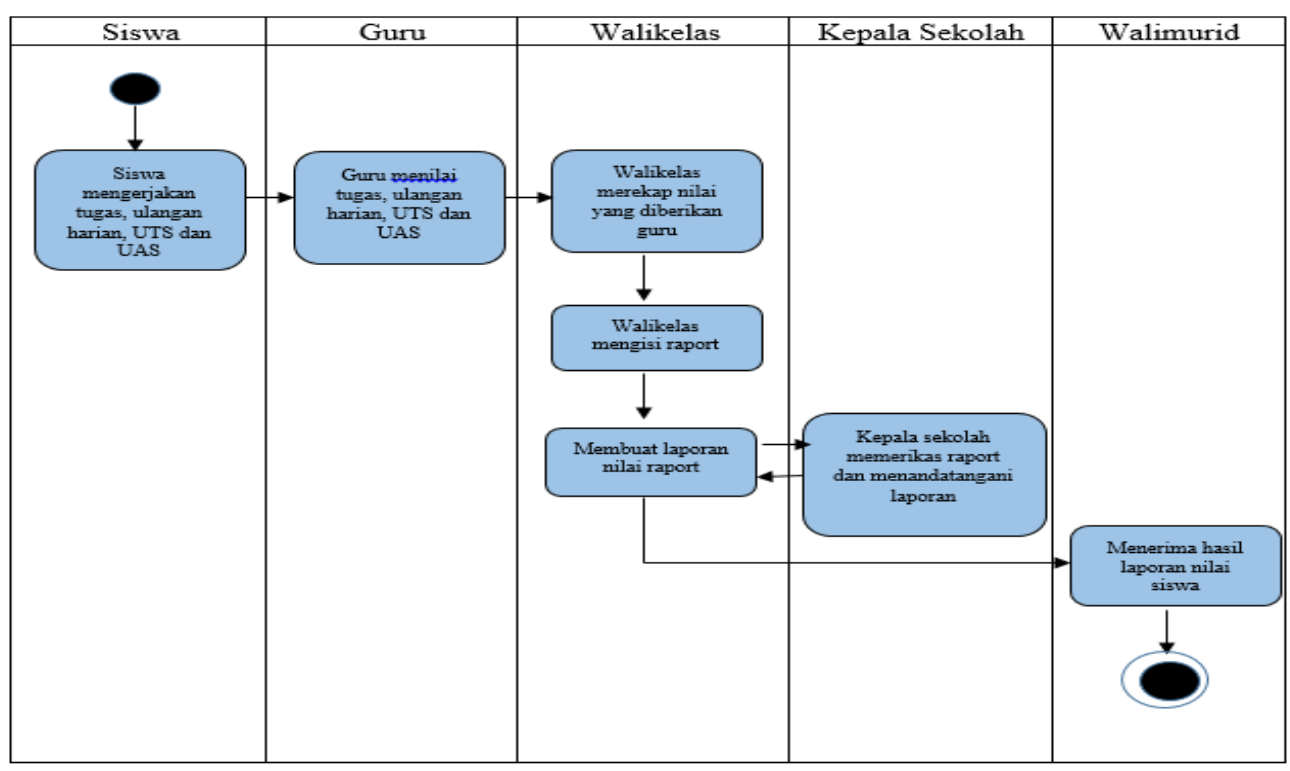


Gambar 2. Sistem pengolahan data nilai yang sedang berjalan

\section{Sistem Yang Diusulkan}

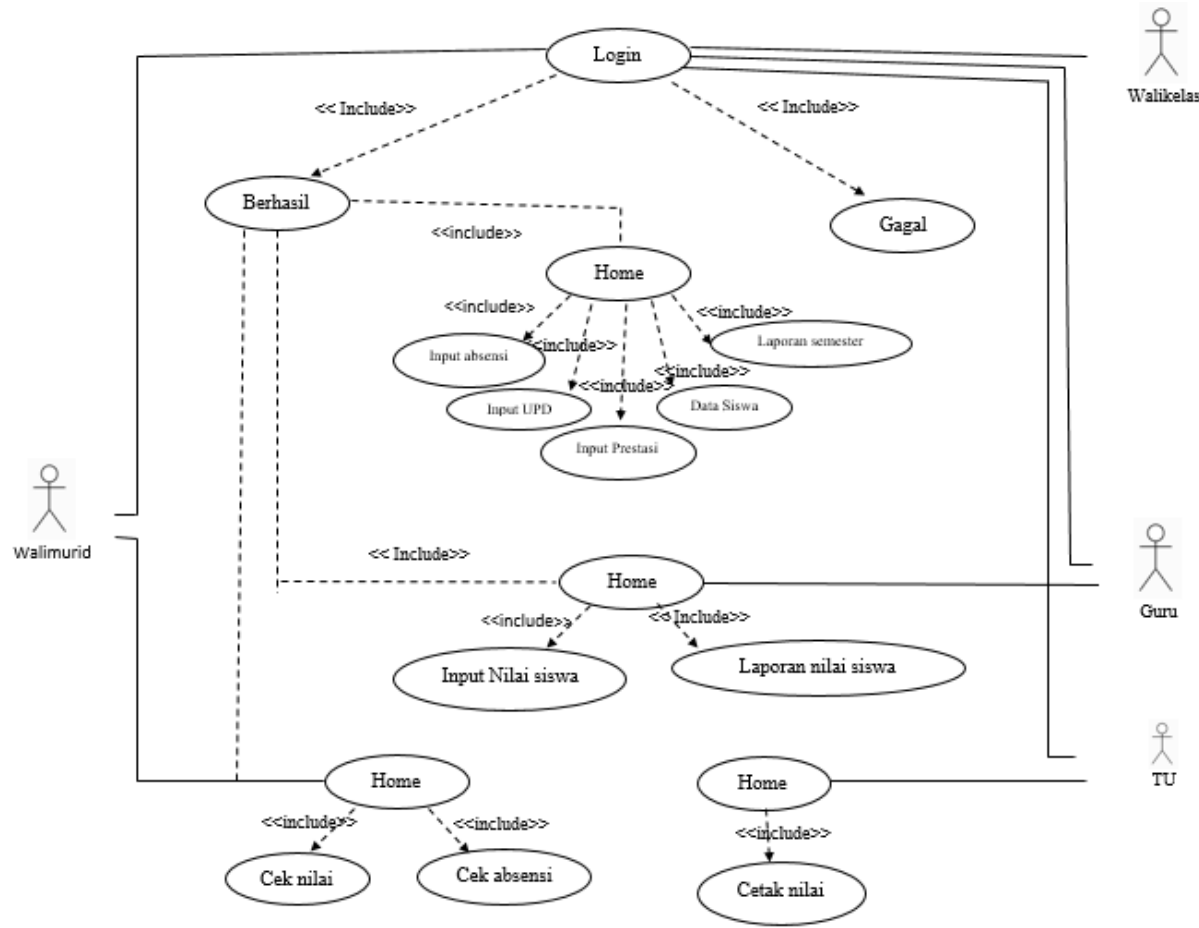

Gambar 3. Sistem yang diusulkan

Pada analisa yang diusulkan, terdapat empat faktor yaitu: Guru, Wali Kelas, TU dan Walimuri.Guru bertugas untuk menginput data nilai siswa sedangkan wali kelas menginput nilai upd, nilai prestasi dan absensi juga ada TU tugasnya mencetak nilai yang akan dibagikan dan walimurid melihat nilai-nilai siswa meliputi absensi dan nilai keseluruhan (Kadir, 2003)

\section{Implementasi}

\section{a. Tampilan menu utama}

Halaman menu utama pada sistem pengolahan data nilai berbasis web pada SMK Swadaya Temanggung, terdapat 4 menu login aktor meliputi Guru, Wali Kelas, Tata Usaha dan Wali Murid. 


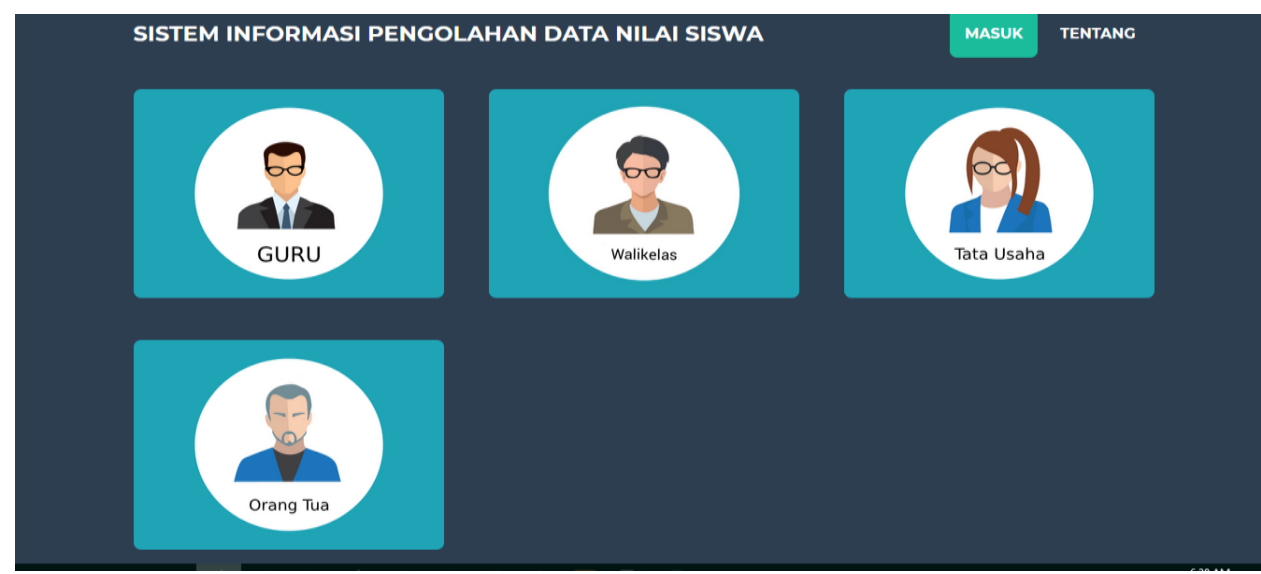

Gambar 4. Tampilan halaman menu utama

\section{b. Tampilan menu login}

Untuk membuka semua menu yang ada pada halaman menu utama diharuskan untuk login terlebih dahulu.

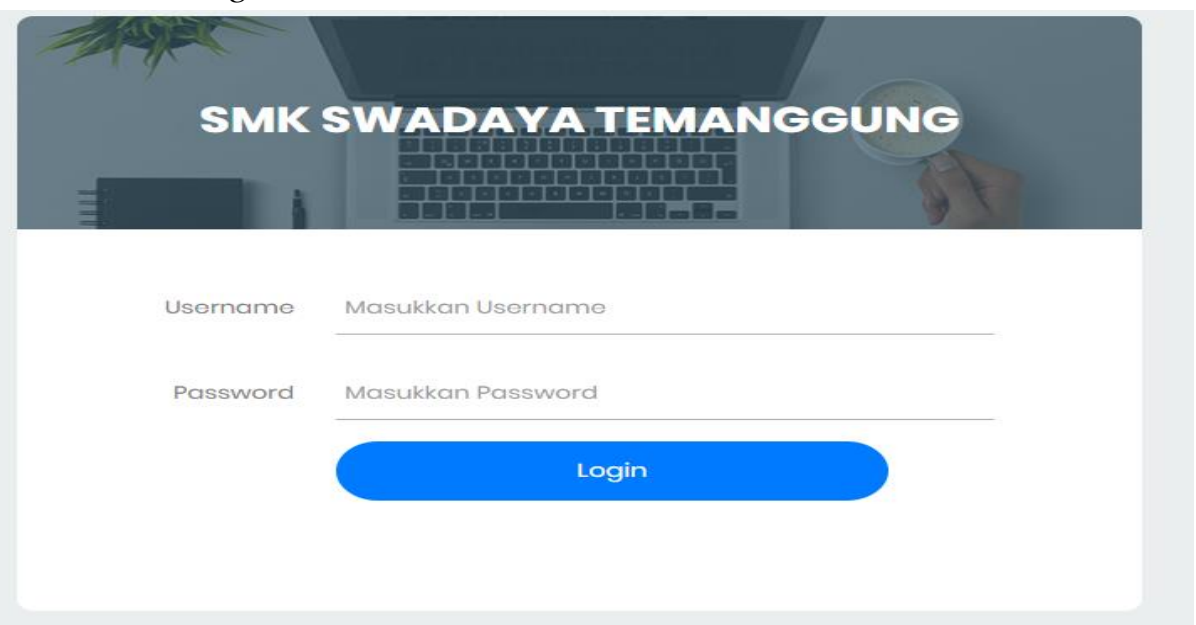

Gambar 8. Tampilan menu login

\section{c. Tampilan Input Nilai}

Menu ini hanya bisa diakses oleh guru untuk menginput nilai siswa.

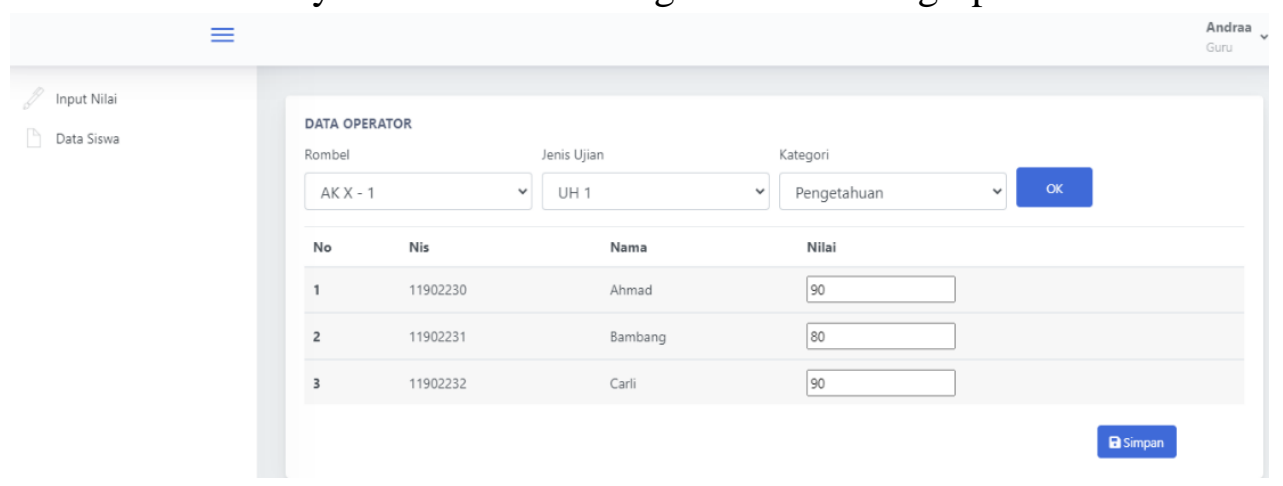

Gambar 9. Tampilan input

\section{d. Tampilan Input Absensi}

Menu ini hanya bisa diakses oleh wali kelas untuk menginput, mengedit dan menghapus absensi siswa 
Sistem Informasi Pengolahan Data Nilai Berbasis Web Pada Smk Swadaya

Temanggung

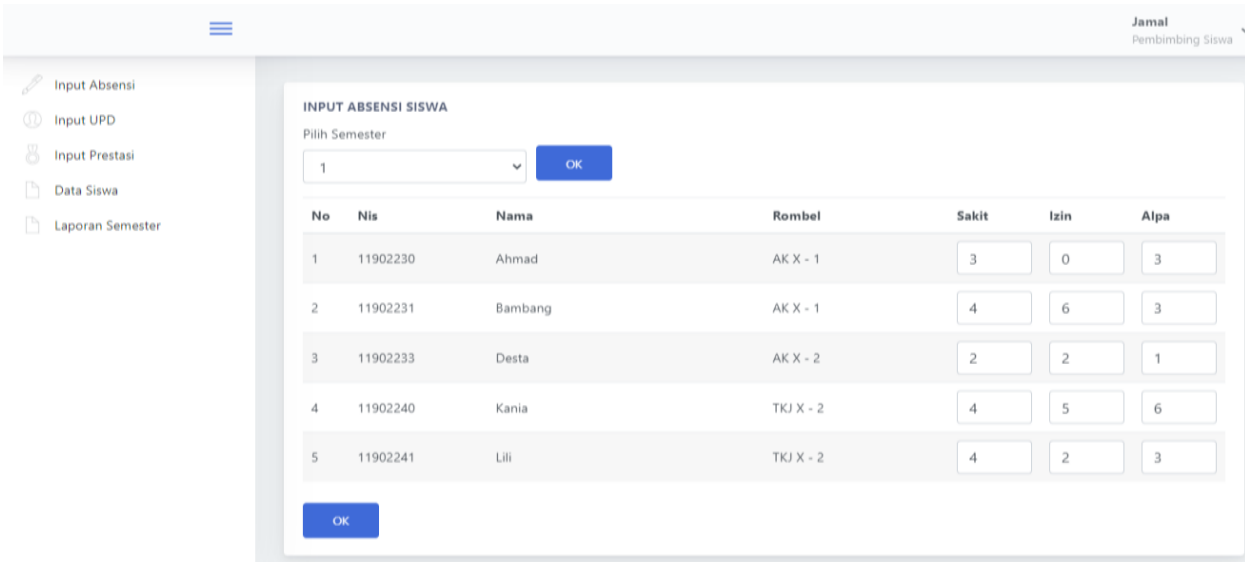

Gambar 8. Tampilan input absensi

\section{e. Tampilan Input UPD Siswa}

Menu data nilai digunakan untuk menginput, mengedit dan menghapus UPD siswa.

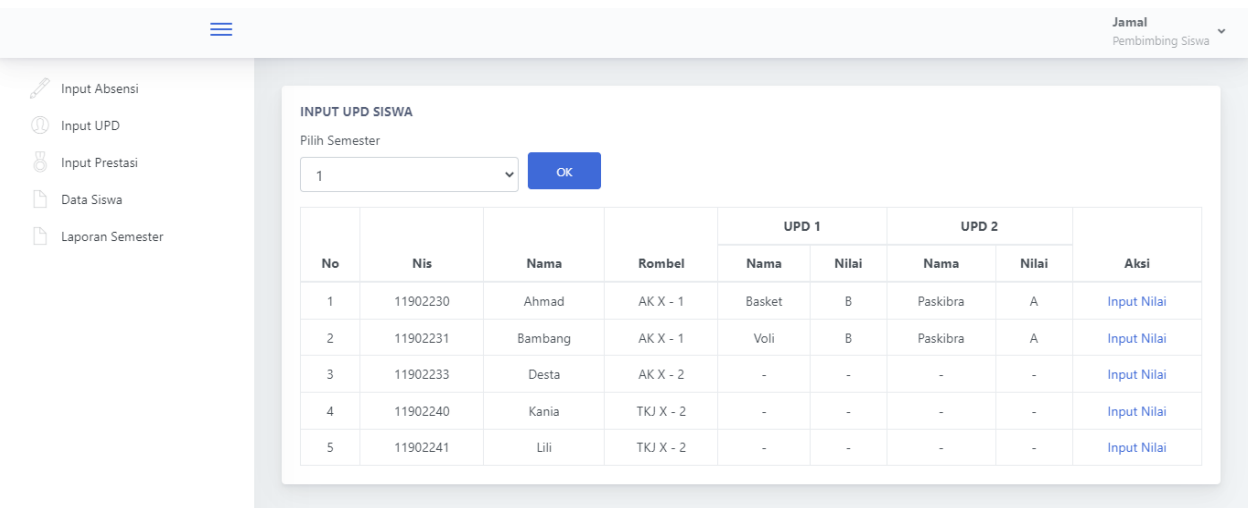

Gambar 9. Tampilan input UPD siswa

\section{f. Tampilan Input Prestasi Siswa}

Menu data nilai digunakan untuk menginput, mengedit dan menghapus prestasi siswa.

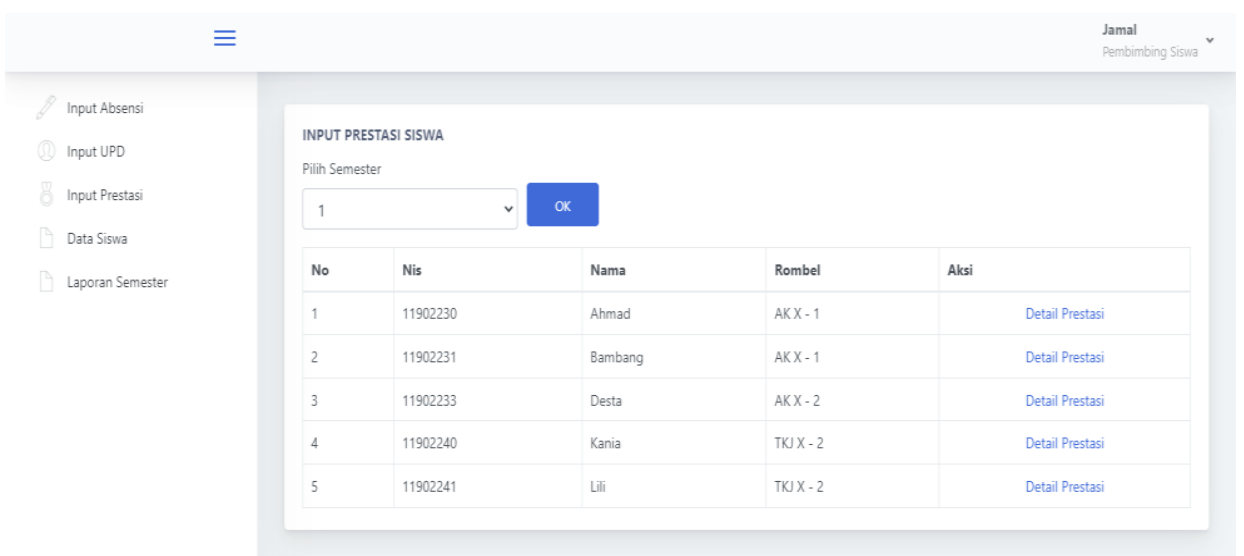

Gambar 10. Tampilan input prestasi siswa 


\section{g. Tampilan laporan semester}

Menu data nilai ini dapat menampilkan detail nilai keseluruhan siswa.

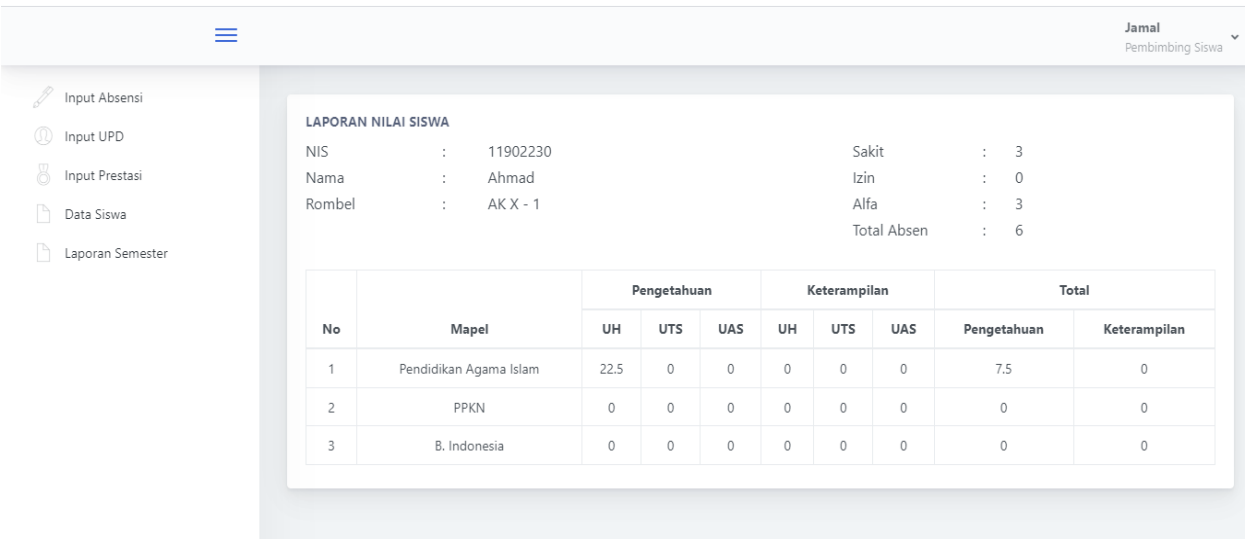

Gambar 11. Tampilan menu data kas masuk

\section{h. Tampilan Cetak Nilai}

Menu ini hanya bisa diakses oleh tata usaha untuk mencetak nilai siswa

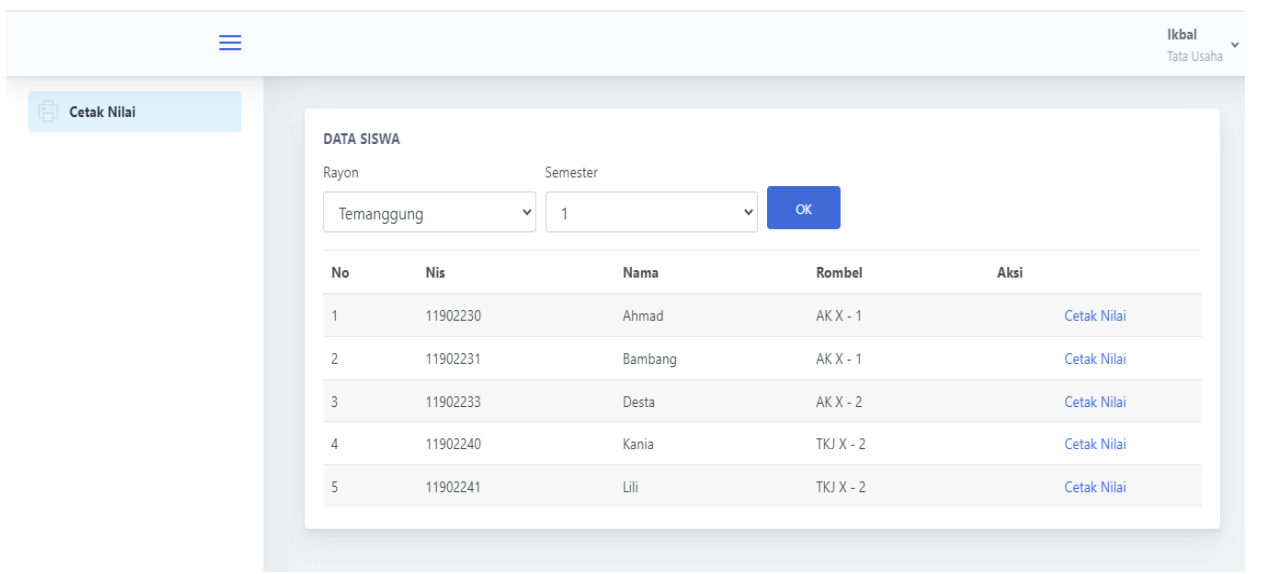

Gambar 12. Tampilan cetak nilai

\section{i. Tampilan Cek Nilai Siswa}

Menu ini hanya bisa diakses oleh wali murid untuk melihat nilai siswa.

\section{HASIL PENILAIAN}

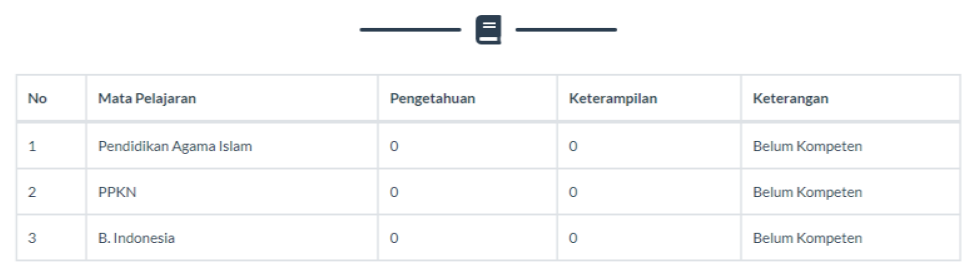

Gambar 13. Tampilan cek nilai

\section{j. Tampilan Cek Absensi Siswa}

Menu ini hanya bisa diakses oleh wali murid untuk melihat laporan kehadiran siswa. 


\section{LAPORAN KEHADIRAN}

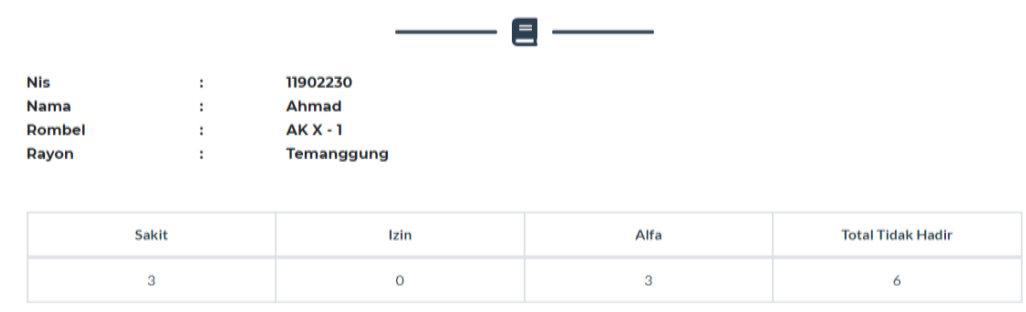

Gambar 14. Tampilan cek absensi Siswa

\section{Pengujian}

Pengujian dilakukan untuk mengetahui apakah fungsi yang telah dibuat berjalan sesuai dengan yang diinginkan.

\section{Rencana pengujian}

Tabel 3. Rencana Pengujian

\begin{tabular}{lll}
\hline \multicolumn{1}{c}{ Pengujian Yang Diuji } & \multicolumn{1}{c}{ Detail Uji } & \multicolumn{1}{c}{ Jenis Pengujian } \\
\hline Menu Login & $\begin{array}{l}\text { Melakukan login kedalam } \\
\text { sistem }\end{array}$ & Black Box \\
\hline Menu Input Data & $\begin{array}{l}\text { Melakukan input, edit dan } \\
\text { hapus data }\end{array}$ & Black Box \\
\hline Menu Laporan & Menampilkan laporan & Black Box \\
\hline
\end{tabular}

2. Hasil Uji

Tabel 4. Hasil Uji Login

\begin{tabular}{llll}
\hline Nama Pengujian & Bentuk Pengujian & Hasil Yang Diharapkan & Hasil \\
\hline & $\begin{array}{l}\text { Menekan tombol } \\
\text { login (Jika benar) }\end{array}$ & $\begin{array}{l}\text { Masuk kehalaman utama dan } \\
\text { membuka semua pilihan } \\
\text { menu }\end{array}$ & Sesuai \\
\cline { 2 - 4 } Login & $\begin{array}{l}\text { Menekan tombol } \\
\text { login (Jika salah) }\end{array}$ & $\begin{array}{l}\text { password pesan “username atau } \\
\text { pasw?" }\end{array}$ & Sesuai \\
\cline { 2 - 4 } & $\begin{array}{l}\text { Menekan tombol } \\
\text { login (Jika data } \\
\text { belum diisi) }\end{array}$ & password harus diisi!” & Sesuai \\
\end{tabular}

Tabel 5. Hasil Uji Input Data

\begin{tabular}{clll}
\hline Nama Pengujian & Bentuk Pengujian & Hasil Yang Diharapkan & Hasil \\
\hline \multirow{2}{*}{ Input } & $\begin{array}{l}\text { Menekan tombol } \\
\text { input }\end{array}$ & $\begin{array}{l}\text { Data berhasil di input dan } \\
\text { tampil pesan "Data berhasil } \\
\text { ditambahkan" }\end{array}$ & Sesuai \\
\hline
\end{tabular}




\begin{tabular}{llll}
\hline & $\begin{array}{l}\text { Menekan tombol } \\
\text { input (Jika data } \\
\text { belum diisi) }\end{array}$ & $\begin{array}{l}\text { Tampil pesan "Pastikan } \\
\text { semua data diisi!" }\end{array}$ & Sesuai \\
\hline \multirow{2}{*}{ Edit } & $\begin{array}{l}\text { Menekan tombol } \\
\text { edit }\end{array}$ & $\begin{array}{l}\text { Data berhasil di } \text { edit dan } \\
\text { tampil pesan "Data berhasil } \\
\text { di } \text { edit" }\end{array}$ & Sesuai \\
\cline { 2 - 4 } & $\begin{array}{l}\text { Menekan tombol } \\
\text { edit (Jika data } \\
\text { belum diisi) }\end{array}$ & $\begin{array}{l}\text { Tampil pesan "Pastikan } \\
\text { semua data diisi!" }\end{array}$ & Sesuai \\
& $\begin{array}{l}\text { Menekan tombol } \\
\text { hapus }\end{array}$ & $\begin{array}{l}\text { Data berhasil di hapus dan } \\
\text { tampil pesan "Data berhasil } \\
\text { dihapus" }\end{array}$ & Sesuai \\
\cline { 2 - 4 } & $\begin{array}{l}\text { Menekan tombol } \\
\text { hapus (Jika data } \\
\text { belum diisi) }\end{array}$ & $\begin{array}{l}\text { Tampil pesan "Pastikan } \\
\text { semua data diisi!" }\end{array}$ & Sesuai \\
\hline Meneka tombol & $\begin{array}{l}\text { Keluar dari menu } \\
\text { penginputan data }\end{array}$ & Sesuai \\
\hline \multirow{2}{*}{ Tutup } & & & \\
\hline
\end{tabular}

Tabel 6. Hasil Uji Laporan

\begin{tabular}{cllc}
\hline Nama Pengujian & Bentuk Pengujian & Hasil Yang Diharapkan & Hasil \\
\hline Laporan & $\begin{array}{l}\text { Menekan menu } \\
\text { laporan }\end{array}$ & Muncul halaman laporan & Sesuai \\
\hline
\end{tabular}

\section{Kesimpulan}

Sistem informasi pengolahan data nilai siswa ini dibangun dan dirancang berbasis web menggunakan PHP MySql untuk memudahkan mengolah data nilai siswa. Sistem informasi pengolahan data nilai siswa berbasis web pada SMK Swadaya Temanggung ini untuk mempermudah guru dalam mengolah nilai siswa agar mendapatkan hasil yang lebih cepat dibanding dengan menggunakan metode yang lama yang masih bersifat manual. 
Sistem Informasi Pengolahan Data Nilai Berbasis Web Pada Smk Swadaya

Temanggung

\section{BIBLIOGRAFI}

Adi Susilo, Sutarjo. (2012). Pembelajaran nilai karakter. Jakarta: Raja Grafindo Persada. Google Scholar.

Dasar, Badan Pusat Kurikulum Dinas Pendidikan. (2006). Kurikulum Tingkat Satuan Pendidikan. Jakarta: Disdik. Google Scholar

Djojonegoro, Wardiman, \& Slamet. (1998). Pengembangan sumberdaya manusia melalui sekolah menengah kejuruan (SMK). Departemen Pendidikan dan Kebudayaan. Google Scholar

Harijono Djojodihardjo (2017) Overview of Coandă MAV as an Aerial Robotic Platform. Google Scolar.

Ian Sommerville (2011), Socio-technical systems: From design methods to systems engineering. Jurnal Intracting With Computer. Google Scholar.

Jogiyanto, H. M. (2005). Prof., Dr. MBA Analisa \& Desain Sistem Informasi: Pendekatan terstruktur teori dan praktek aplikasi bisnis. Yogyakarta: CV Andi Offset. Google Scholar

Kadir, Abdul. (2003). Pengenbangan Sistem Informasi. Yogyakarta: Penerbit Andi. Google Scholar

McLeod, Raymond, \& Schell, George. (2004). Sistem Informasi Manajemen Edisi Kedelapan. Indeks: Jakarta. Google Scholar 